\title{
Is safe surgery possible when resources are scarce?
}

\author{
Nathan N O'Hara ${ }^{1,2}$
}

\begin{abstract}
${ }^{1}$ Department of Orthopaedics, University of British Columbia, Vancouver, British Columbia, Canada

${ }^{2}$ Office of Pediatric Surgical Evaluation and Innovation, BC Children's Hospital, Vancouver, British Columbia, Canada
\end{abstract}

\section{Correspondence to}

Nathan N O'Hara, Department of Orthopaedics, University of British Columbia, Room 3114910 West 10th Ave, Vancouver, British Columbia, Canada V5z 1M9;

nathan.ohara@vch.ca

Accepted 8 May 2015 Published Online First 21 May 2015

\begin{abstract}
The greatest burden of surgical disease exists in low- and middle-income countries, where the quality and safety of surgical treatment cause major challenges. Securing necessary and appropriate medical supplies and infrastructure remains a significant and under-recognised limitation to providing safe and high-quality surgical care in these settings. The majority of surgical instruments are sold in high-income countries. Limited market pressures lead to superfluous designs and inflated costs for these devices. This context creates an opportunity for frugal innovation - the search for designs that will enable low-cost care without compromising quality. Although progressive examples of frugal surgical innovations exist, policy innovation is required to augment design pathways while fostering appropriate safety controls for prospective devices. Many low-cost, high-quality medical technologies will increase access to safe surgical care in low-income countries and have widespread applicability as all countries look to reduce the cost of providing care, without compromising quality.
\end{abstract}

Although the greatest burden of surgical disease exists in low-income and middle-income countries, ${ }^{1}$ surgical capacity in those countries remains very limited. ${ }^{3}$ Populations in these regions are predominantly rural, ${ }^{4}$ and the few dollars required for a bus ride to the hospital are often an insurmountable barrier to care. ${ }^{5}$ Those patients that successfully navigate through the barriers to access surgery in low-income countries are frequently greeted with lengthy queues, overcrowding and poor facilities as well as shortage of trained personnel. ${ }^{6}$

Tremendous international efforts are now being made to improve access to surgery through workforce initiatives. ${ }^{7} 8$ The expansion of surgical and perioperative training programmes in low-income and middle-income countries has resulted in a welcome increase in the number of skilled personnel in these regions. ${ }^{9}{ }^{10} \mathrm{~A}$ more neglected problem to providing safe surgery in these settings, however, remains the challenges associated with securing the necessary and appropriate medical supplies and infrastructure. ${ }^{6}$ And, as this article shows, innovation to solve these challenges is likely to require not just technical ingenuity but policy creativity too.

Many hospitals in low-income countries lack basic equipment that works reliably. For example, a properly functioning autoclave sterilizer is a critical baseline component to providing safe surgical care in any setting. But without routine maintenance and testing, autoclaves often break down or malfunction. The associated risks of surgical infection may then call into question the value of the intervention, underlining the broader point that improving access without ensuring safety and quality may be misguided.

The often-unreliable performance of surgical equipment in low-resource settings should be predictable. Most equipment was simply not designed for these settings, but instead for hospitals with reliable electricity, constant water pressure, large boiler infrastructure and pneumatic systems. Surgical equipment is sold with profit margins that account for technical support and service contracts, meaning that it is effectively not available for hospitals in low-income countries. ${ }^{11}$ These hospitals therefore acquire much of their equipment through donations, often when it is years past its prime and lacks all necessary components, and almost always without a service contract. The impact of using surgical equipment without routine maintenance and the supportive infrastructure it was designed for is unknown, given the paucity of data on long-term surgical outcomes in lowincome countries. ${ }^{12}$

Yet the problem cannot necessarily be solved simply by calling for more money 
to be spent on surgical infrastructure in low-income countries, since that is not a viable option at present. Further, it is not necessary that low-income countries adopt exactly the same equipment and supply arrangements as those used in high-income countries. Surgical instruments are all too often superfluous in their design and unnecessarily expensive, reflecting the more general truth that, globally, healthcare costs too much. ${ }^{13}$ This challenge inspires frugal innovation - the search for designs that will enable low-cost care without compromising quality. ${ }^{14}$

One example of this kind of frugal innovation is a surgical device, designed by colleagues at the University of British Columbia (UBC), which exemplifies the possibilities for developing high-quality, low-cost surgical devices for the world's poorest patients. The device seeks to address the problem of under-supply of surgical drills in low-income countries. In high-income countries, the surgical drills used for the fixation of orthopaedic fractures cost as much as a new car. They are unaffordable for low-resource hospitals, who instead often revert to an egg-beater-like manual hand drill for treating fractures. Even when the bearings on these manual hand drills are well maintained, they are tedious to operate and difficult to control, compromising the quality of care and safety of the patient and surgeon.

The UBC engineering team discovered that certain models of hardware drills (available from standard hardware stores) have the same torque and rotation speed as the surgical drill that is sold at 300 times the price. Designed for the durability demands of a construction site, a hardware drill is an ideal solution for surgical care in low-resource setting. However, hardware drills cannot be sterilized in a steam autoclave.
The team of engineers came up with a solution to this obstacle: a two-part sterilizable drill cover (figure 1). The cover envelops the drill in medical-grade cloth funnelling into a surgical-grade stainless steel ring. The second part, a stainless steel interface, creates a perfect enclosure and allows adjustment for the various surgical attachments required for the orthopaedic procedures.

The design has been prototyped in several lowresource settings including Uganda, Syria and Papua New Guinea with very positive feedback. Surgeons have commented that the performance of the device is comparable to high-end models and a vast improvement over the manual-powered models. A recently completed study compared the speed and accuracy of the drill cover device with the high-end models and found no significant difference in performance, while both the drill cover and high-end models significantly outperformed manual drills on both metrics. ${ }^{15}$ Prior to the development of the drill cover, many surgeons in low-resource settings opted to use unsterile hardware drills (without a cover) to treat fractures, hedging that the risk of infection from an unsterile drill was better than an alternative or no treatment.

Effectiveness is not the end of the story for surgical equipment, however, since these are medical devices being used in high-risk situations: regulatory controls are clearly vital to patient and provider safety. At present-as is the case with the surgical drill coverthere is a tendency to rely on approvals gained from high-income countries, but this is not a sustainable solution for most innovation since it presents a powerful barrier to frugal innovation. ${ }^{16}$ The fees can quickly offset any potential profits gained through device sales, thus deterring frugal innovation in its

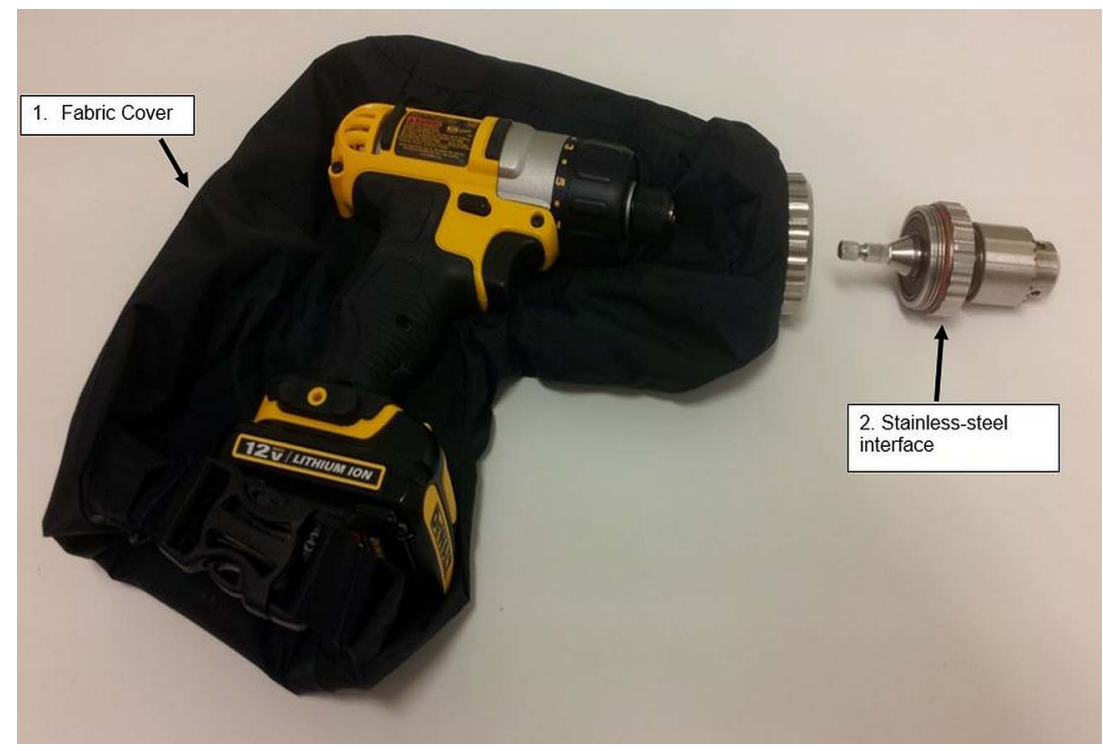

Figure 1 The drill cover system is composed of a hardware drill plus two detachable parts. The fabric cover (1) is constructed of a double-layered medical fabric typically used for surgical drapes and gowns. The stainless-steel interface (2) comprises a shaft, three-tooth adjustable chuck and encased bearings that enable the operator to use various sizes of surgical drill bits. 
early stages. Most low-income countries have very small markets for medical devices ${ }^{11}$ and therefore have little opportunity to use tax revenues to support the development of their own agencies. Frugal innovation means that, along with technical innovation, policy innovation is likely to be needed too.

To encourage more appropriate and locally developed solutions and decrease donor reliance, novel ways of coordinating activity, sharing risk and pooling information will be needed. International agencies, such as the WHO, ${ }^{17}$ will have an important role. This might include, for example, creating collaborative networks for healthcare professionals to provide post-market surveillance on new medical devices. A curated online system to report adverse events attributable to new devices could, for instance, temper demand for the product, protect prospective patients and create a network of information to drive future frugal innovation.

Health practitioners, globally, seek optimal treatments for their patients and, when faced with limited options, will often seek unconventional solutions. Low-cost, high-quality medical technologies have an important role in increasing access to safe surgical care in low-income countries and may have widespread applicability as all countries look to reduce the cost of providing care, without compromising quality. This makes finding regulatory solutions just as imperative as technical ones, and will require global commitment to advance.

Correction notice This article has been corrected since it was published Online First. The first two lines of the Abstract have been included.

Acknowledgements The author would like to thank Dr Mark Ansermino for providing guidance on regulatory policy for frugal innovation and acknowledge the information provided by the drill cover design team from the University of British Columbia and Arbutus Medical.

Competing interests None declared.

Provenance and peer review Not commissioned; internally peer reviewed.

\section{REFERENCES}

1 Debas HT, Donkor P, Gawande A, et al. Disease control priorities, third edition: volume 1. Essential surgery. Washington DC: World Bank, 2015.
2 Weiser TG, Regenbogen SE, Thompson KD, et al. An estimation of the global volume of surgery: a modelling strategy based on available data. Lancet 2008;372:139-44.

3 Alkire BC, Raykar NP, Shrime MG, et al. Global access to surgical care: a modelling study. Lancet Glob Health 2015.

4 United Nations, Department of Economic and Social Affairs, Population Division (2014). World Urbanization Prospects: The 2014 Revision, Highlights (ST/ESA/SER.A/352).

5 O'Hara NN, Mugarura R, Slobogean GP, et al. The orthopaedic trauma patient experience: a qualitative case study of orthopaedic trauma patients in Uganda. PLoS ONE 2014;9: e110940.

6 Grimes CE, Bowman KG, Dodgion CM, et al. Systematic review of barriers to surgical care in low-income and middle-income countries. World J Surg 2011;35:941-50.

7 Tollefson TT, Larrabee WF Jr. Global surgical initiatives to reduce the surgical burden of disease. JAMA 2012;307:667-8.

8 Spiegel DA, Gosselin RA. Surgical services in low-income and middle-income countries. Lancet 2007;370:1013-15.

9 Luboga S, Macfarlane SB, von Schreeb J, et al. Increasing access to surgical services in sub-Saharan Africa: priorities for national and international agencies recommended by the Bellagio Essential Surgery Group. PLoS Med 2009;6: e1000200.

10 Hoyler M, Finlayson SR, McClain CD, et al. Shortage of doctors, shortage of data: a review of the global surgery, obstetrics, and anesthesia workforce literature. World J Surg 2014;38:269-80.

11 US Department of Commerce. Medical device industry assessment. http:/ita.doc.gov/td/health/medical\%20device\% 20industry\%20assessment $\% 20$ final $\% 20 \mathrm{ii} \% 203-24-10 . p d f$ (accessed 4 Mar 2015).

12 Ozgediz D, Hsia R, Weiser T, et al. Population health metrics for surgery: effective coverage of surgical services in low-income and middle-income countries. World J Surg 2009;33:1-5.

13 Kaplan RS, Porter ME. How to solve the cost crisis in health care. Harv Bus Rev 2011;89:46-52, 54, 56-61 passim.

14 Anner J. Emerging economies drive frugal innovation. Bull World Health Organ 2013;91:6-7.

15 Lam JMK, Buchan LL, Potter J, et al. Surgical device innovation for low-resource settings: an alternative for bone drilling. Can J Surg 2015. In Press.

16 Preston C, Valdez ML, Bond K. Strengthening medical product regulation in low- and middle-income countries. PLoS Med 2012;9:e1001327.

17 World Health Organization. The development of medical device policies. Geneva, Switzerland: World Health Organization, 2011. 